\title{
Infantile amnesia: forgotten but not gone
}

\author{
Stella Li, ${ }^{1}$ Bridget L. Callaghan, and Rick Richardson \\ School of Psychology, The University of New South Wales, Sydney, NSW 2052, Australia
}

\begin{abstract}
Unlike adult memories that can be remembered for many years, memories that are formed early in life are more fragile and susceptible to being forgotten (a phenomenon known as "infantile" or "childhood" amnesia). Nonetheless, decades of research in both humans and nonhuman animals demonstrate the importance of early life experiences on later physical, mental, and emotional functioning. This raises the question of how early memories can be so influential if they cannot be recalled. This review presents one potential solution to this paradox by considering what happens to an early memory after it has been forgotten. Specifically, we describe evidence showing that these forgotten early-acquired memories have not permanently decayed from storage. Instead, there appears to be a memory "trace" that persists in the face of forgetting which continues to affect a variety of behavioral responses later in life. Excitingly, the discovery of this physical trace will allow us to explore previously untestable issues in new ways, from whether forgetting is due to a failure in retrieval or storage to how memories can be recovered after extended periods of time. A greater understanding of the characteristics of this memory trace will provide novel insights into how some memories are left behind in childhood while others are carried with us, at least in some form, for a lifetime.
\end{abstract}

Memory, along with most other cognitive abilities, develops across the lifespan (Ofen and Shing 2013). While memories acquired in adulthood are generally well remembered and persistent (e.g., Gale et al. 2004), memories formed earlier in development are usually quite fragile and rapidly forgotten (a phenomenon known as "infantile" or "childhood" amnesia [Campbell and Campbell 1962; Spear and Parsons 1976; Hayne 2004; Hayne and Jack 2011]). The fact that early memories are so fragile has resulted in a great deal of controversy over the importance of early experiences on later functioning (e.g., Fraley et al. 2013). Specifically, if early experiences cannot be explicitly recalled, how can they influence an individual's functioning later in life? Although this question remains unanswered, there is an overwhelming amount of evidence supporting the idea that early experiences are critical for later functioning. For example, there is substantial evidence that the quality of maternal care experienced early in life affects the behavioral, neural, and physiological responses of the offspring as they mature. In a striking series of studies, Tottenham and colleagues examined children who experienced maternal deprivation in the first two years of life (i.e., had been reared in an orphanage). In one study it was reported that these individuals were more likely to experience depression in adolescence (Goff et al. 2013). Further, on a neural level, they also exhibited altered maturation of the nucleus accumbens, a structure involved in reward learning. In another study, these individuals exhibited amygdala hyperactivity as well as accelerated maturation of amygdala-prefrontal cortex connectivity (Gee et al. 2013); both of these structures are important for emotion regulation in humans (Hartley and Phelps 2013).

Numerous animal studies have also demonstrated the importance of early experiences for later functioning. For example, it has been reported that infant rats whose mothers engaged in a high rate of arched back nursing and licking/grooming exhibit markedly lower hormonal reactions in a stressful situation in adulthood (Liu et al. 1997). In addition, these animals are more exploratory, and perform better at spatial learning and memory tasks (for review, see Champagne and Curley 2009). It has also

\section{${ }^{1}$ Corresponding author}

E-mail ssli@psy.unsw.edu.au

Article is online at http://www.learnmem.org/cgi/doi/10.1101/lm.031096.113. been suggested that specific early experiences may be the basis of adult psychopathologies (e.g., Jacobs and Nadel 1985; Mineka and Zinbarg 2006). Hence, although early experiences are rapidly forgotten, such experiences do appear to have a lasting impact. Here, we explore some of the ways in which early memories continue to have an influence on later functioning despite being "forgotten."

\section{Infantile amnesia}

Traditionally, forgetting is defined as the inability to recall and express a memory on a behavioral level (e.g., free recall in humans, a learned avoidance response in rodents). Although memory loss can be observed in animals of all ages, it is most common in younger and aged animals, each of which exhibit a rapid rate of forgetting compared to adult animals. The faster rate of forgetting in the young is a well-documented phenomenon. For example, in their now-classic study Campbell and Campbell (1962) trained rats ranging in age from $18 \mathrm{~d}$ (infants) to $100 \mathrm{~d}$ (adults) on an aversively motivated avoidance task. When tested immediately after training animals of all ages showed high, and comparable, levels of avoidance. As the retention interval increased, however, marked age differences in performance were observed. Specifically, the infant rats exhibited substantial forgetting after $7 \mathrm{~d}$ and complete forgetting after $21 \mathrm{~d}$. In contrast, the adult rats exhibited perfect retention even after $42 \mathrm{~d}$, the longest interval tested. Similar results have been reported with humans in a nonfear based task. As one example, in a series of experiments Rovee-Collier and colleagues have shown that retention in human infants trained on an operant procedure (e.g., the mobile conjugate reinforcement task, where the infant learns to kick one leg to produce movement in an overhanging mobile, or the train task, where the infant learns to press a manipulandum to cause an electric train to move) increases monotonically with age over the first years of life (for review,

(C) $2014 \mathrm{Li}$ et al. This article is distributed exclusively by Cold Spring Harbor Laboratory Press for the first 12 months after the full-issue publication date (see http://learnmem.cshlp.org/site/misc/terms.xhtml). After 12 months, it is available under a Creative Commons License (Attribution-NonCommercial 3.0 Unported), as described at http://creativecommons.org/licenses/by-nc/ $3.0 /$. 
see Rovee-Collier and Cuevas 2009). Thus, the studies described above, along with many others, clearly show that memories acquired early in life are forgotten much more quickly than those acquired later in life, at least in terms of conscious recollection or overt behavioral expression of the memory. ${ }^{2}$

Although we have long been aware of the robust phenomenon of infantile amnesia, in the past 50 years there have been surprisingly few advances in our understanding of the physiological bases of this rapid forgetting. However, several recent papers have suggested potential molecular and structural mechanisms that could be involved in infantile amnesia (e.g., Josselyn and Frankland 2012; Frankland et al. 2013; Callaghan et al. 2014). These potential mechanisms are largely derived from recent studies on the molecular and structural bases of memory in adults. That is, infantile amnesia may be due to the immaturity of one, or more, of these mechanisms in infancy. Determining how the various processes already shown to be important in memory in adulthood change across early development is likely to lead to a much better mechanistic understanding of infantile amnesia. However, in this brief review, we focus on a different approach toward understanding infantile amnesia. This approach focuses on the possibility that at least some part of these apparently forgotten early memories persists beyond the point in time where the memory is overtly expressed. This "trace" of the memory, although not normally expressed in a standard retention test, can still markedly affect the participant's behavior in a number of ways. The following sections explore the various ways through which the lasting influence of this trace on later functioning can be observed.

\section{Implicit versus explicit memory}

It has long been noted that the pronounced forgetting observed in adult amnesiacs primarily occurs with certain types of memories (for reviews, see Schacter and Buckner 1998; Moscovitch 2010). That is, these individuals typically exhibit difficulties with verbal recall of a past event even though they show altered behavioral responses that could have only resulted from having that experience. For example, an adult amnesiac might not recall learning to play a particular song on a piano, but yet is able to perform it. This distinction is referred to as the difference between explicit and implicit memory. A similar dissociation is observed following forgetting of early memories, where there is a lingering influence of the experience even though it is not explicitly recalled.

One example which shows that an enduring memory trace of an early experience can influence subsequent behavior in humans despite a lack of conscious recollection is provided by the research of Newcombe and her colleagues (for review, see Lloyd and Newcombe 2009). In one experiment children were given a recognition test for faces of classmates from preschool. Some children correctly recognized their old classmates while other children did not. Regardless of accuracy in recognition, however, children exhibited a similar skin conductance response to the faces of their old classmates relative to the faces of unfamiliar children. In another study, 3-yr-olds, 5-yr-olds, and adults were shown pictures from a story book. When tested 3 mo later, the 3-yr-olds' verbal recognition of the pictures was at chance while the 5-yr-olds and adults performed significantly better. Despite this difference

\footnotetext{
${ }^{2}$ Although memories acquired early in life are more rapidly forgotten compared to those acquired later in life, it should be noted that the sensory modality of the CS can markedly affect the rate of this forgetting. As a prime example, there are several studies showing that infant rats retain olfactory-based memories well into adulthood (Sevelinges et al. 2008). Nonetheless, when direct age comparisons have been made for retention of olfactory-based learning, it is still the case that the younger animals forget more quickly than older animals (Markiewicz et al. 1986).
}

in explicit memory of the pictures there was no developmental difference on a perceptual priming task. That is, when asked to name an out-of-focus picture that progressively came into focus, all three age groups performed better (i.e., named the picture sooner) with familiar pictures from the storybook than with novel pictures. Findings like these have led some researchers in the field of human memory development to suggest that early memories leave at least a partial trace that continues to influence later functioning despite not being explicitly recalled (e.g., Sroufe et al. 1990).

The idea that an unexpressed memory trace might have an "implicit" effect on later performance in rodents was recently explored by Li and Richardson (2013). In that study, the effect of a memory acquired during infancy, but then forgotten, on the neurobiological mechanisms mediating future learning experiences was examined. In adult animals, it is well-established that the cellular mechanisms underlying initial learning ("acquisition") involve a series of intracellular signals, one of which is the activation of $N$-methyl-D-aspartate receptors (NMDArs) (Kandel 2001; Schafe et al. 2001). However, when the same learning experience occurs again ("reacquisition") NMDArs are no longer required (e.g., Sanders and Fanselow 2003; Wiltgen et al. 2011). This is referred to as a "switch" from NMDAr-dependent acquisition to NMDAr-independent reacquisition. Li and Richardson (2013) explored whether this switch to NMDAr-independent reacquisition still occurred if the original learning had been forgotten. Infant rats were trained at $17 \mathrm{~d}$ of age with noise CS-shock US pairings. After 2 wk these infant rats demonstrated complete forgetting by exhibiting negligible levels of conditioned fear (as assessed through CS-elicited freezing). Reacquisition following forgetting was NMDAr-independent regardless of whether reacquisition occurred 2 or $7 \mathrm{wk}$ after training (forgetting was observed at both intervals). Importantly, the switch from NMDAr-dependent acquisition to NMDAr-independent reacquisition only occurred if the experience at $17 \mathrm{~d}$ of age was an associative learning experience (i.e., CS-US pairings) and not merely an aversive experience (i.e., unpaired noise-shock presentations). Hence, it appears that early memories can have a long-lasting influence on subsequent learning, altering the cellular mechanisms involved in learning later in life, even though they are no longer overtly expressed at the behavioral level. Interestingly, the transition to NMDAr-independent reacquisition is not observed in adult rats following anisomycin-induced amnesia (Hardt et al. 2009) or following extinction training in conjunction with administration of fibroblast growth factor-2 (Graham and Richardson 2011) as these manipulations appear to permanently alter or erase the original memory trace. Taken together, the results of these studies suggest that the switch from NMDAr-dependent acquisition to NMDAr-independent reacquisition could be a useful procedure for assessing whether some representation of a memory which is forgotten at a behavioral level is still maintained in the brain.

\section{Memory reinstatement/reactivation}

The terms "reinstatement" and "reactivation" both refer to a situation where an apparently forgotten memory is recovered (i.e., is now overtly expressed at test). The difference between the two terms is that "reinstatement" usually is used in studies where repeated, periodic reminders are given throughout the retention interval, while "reactivation" usually is used in studies where a single reminder is given at the end of the retention interval (Spear and Parsons 1976).

The obvious implication of the findings described immediately above is that infantile forgetting is not due to a loss of the early-acquired memory from storage. In other words, this 
forgetting must be due to a retrieval failure. Additional evidence for this claim is provided by a study by Campbell and Jaynes (1966) who reported that infantile amnesia in rats could be alleviated by "reminders" given periodically throughout the retention interval. Since that study there has been a plethora of additional studies supporting this finding in a variety of tasks and in both humans and nonhuman subjects. For instance, Spear and Parsons (1976) conditioned 16-d-old rats (infants) to fear a light CS by pairing it with a footshock US. Animals were tested $28 \mathrm{~d}$ after training and, as expected, substantial forgetting occurred (i.e., infantile amnesia was observed). However, $24 \mathrm{~h}$ prior to test some animals were given a single shock presentation. Animals that received the pretest shock "reminder" exhibited high levels of fear of the light CS at test. To ensure that the reminder shock did not cause any learning by itself, a separate group of animals were not trained but were given the shock prior to test. The light CS did not elicit fear in these animals, demonstrating that the treatment alleviated forgetting by reactivating the original memory rather than producing sufficient new learning to lead to the behavioral response of interest. Although most early studies of this phenomenon used footshock as the reminder cue, later studies showed that infantile amnesia could be attenuated through other pretest treatments, such as hormonal or pharmacological agents (e.g., epinephrine [Haroutunian and Riccio 1977] and FG-7142 [Kim et al. 2006]). All of these studies, as well as those described earlier in the section on explicit/implicit memory, show that some representation of the original memory formed in infancy must still be present later in development despite the fact that the memory is not easily retrieved or overtly expressed.

Similar findings have been reported in human infants. For example, Davis and Rovee-Collier (1983) trained 8-wk-old infants on an operant conditioning task where the infant learned to kick their foot in order to move a mobile suspended above them. Two weeks after training, all infants showed complete forgetting of this task. However, infants showed little to no forgetting if they had received a reminder treatment (exposure to the moving mobile) 24 $\mathrm{h}$ prior to the long-term retention test. Thus, just like in the rodent studies, even when forgetting occurs on a behavioral level, memories acquired by infant humans are not permanently lost or erased.

\section{Empirical evidence for a physical memory trace after infantile forgetting}

The studies described in the two preceding sections suggest that there must be some neural representation of the early-acquired memory even when it is not behaviorally expressed. Evidence for such a physical trace was recently provided in a study by Kim et al. (2012). In that study, 16- and 23-d-old rats were given noise CS-shock US pairings. When tested immediately after training, rats at both ages showed similar levels of conditioned fear (as assessed through CS-elicited freezing). When tested $2 \mathrm{~d}$ later, however, only the 23 -d-old rats continued to exhibit fear to the CS, while the 16-d-old rats showed low levels of CS-elicited freezing, indicating forgetting. Following test, the amount of phosphorylated mitogen-activated protein kinase (pMAPK) in the amygdala was analyzed using immunohistochemistry. Despite failing to behaviorally express the memory, the 16-d-old rats tested at the 2-d interval had heightened pMAPK activity in the amygdala, comparable to that observed in the 23-d-old rats who had exhibited high levels of freezing at test. Importantly, both of these groups differed in levels of amygdala pMAPK activity relative to same-age animals given explicitly unpaired presentations of the CS and US at training and then tested $2 \mathrm{~d}$ later; the rats in this unpaired condition did not express fear of the CS. These results sug- gest that pMAPK levels in the amygdala track past learning history and may be a long-term marker of fear memory storage. That study provided the first neural evidence for a memory trace which persists in the face of infantile forgetting.

The discovery of a neural marker of past learning experience that persists despite forgetting on the behavioral level may prove useful in a number of ways. For example, although the studies described above on memory reinstatement/reactivation clearly demonstrate that many instances of infantile forgetting are due to a retrieval failure, this does not mean they always are. That is, forgetting of early memories may go through two phases. In the first phase, the memory is no longer explicitly expressed, but can be recovered if an appropriate reminder treatment is given prior to test. However, if the memory remains in this dormant state (i.e., available but not accessible) long enough, then it may decay sufficiently such that there is no longer a representation of it in the brain (see Callaghan et al. 2014, for a consideration of various neural and molecular processes that could be involved in infantile amnesia). In other words, infantile forgetting, and forgetting more generally, could sometimes be due to a retrieval failure and other times to a storage failure; the presence or absence of the physical trace could potentially distinguish between the two cases.

The observation of a successful reinstatement/reactivation effect clearly shows that any observed forgetting was due to a retrieval failure. However, the failure to detect such an effect does not necessarily mean that the memory trace has decayed from storage; rather, such a result could be due to an ineffective reminder cue. This issue has long been noted, but without having any independent evidence of the memory trace, other than successful reactivation, it has not been possible to test these various possibilities. The demonstration of a detectable neural signal resulting from a specific learning experience could be very useful in this situation. That is, if animals fail to recover a memory following a reminder treatment, but they exhibit evidence of the physical trace (e.g., altered pMAPK activity in the amygdala), then a stronger conclusion can be made that the particular reminder treatment used was ineffective in that situation.

It will be interesting to determine whether other neural markers of memory can also be used to explore the issue of whether infantile forgetting is due to a storage or retrieval failure. As one example, Han and colleagues took advantage of the finding that changes in cyclic-AMP response element binding protein (CREB) expression plays a role in the formation of a memory trace. Specifically, they reported that experimentally increasing CREB expression in subpopulations of neurons in the lateral amygdala following auditory fear conditioning resulted in the recruitment of those neurons into the memory trace (Han et al. 2007). In a subsequent study they showed that deletion of these CREB-overexpressing neurons reduced memory expression (Han et al. 2009). It is currently unknown whether the same results would be observed in the infant animal. In other words, is CREB expression also important for the formation of a memory trace in the infant animal? If so, then heightened CREB expression in the amygdala, especially at long intervals following initial learning, may be used to predict the success of memory reinstatement/reactivation.

The discovery of these various neural markers can help us to distinguish between retrieval- and storage-based failures in memory. However, one issue that requires further investigation is why the animal exhibits forgetting even when there is a neural signature of the memory persisting in the brain. As previously mentioned, it is likely that forgetting occurs in stages. Thus, it is possible that the strength of the memory trace also degrades in stages. For instance, it may be that the behavioral expression or explicit recall of a memory requires the whole (or nearly whole) memory trace to be present in the brain. When an animal forgets 
but the memory can still be reactivated and retrieved, then a partial memory trace may be observed. The final stage, when an animal forgets and the memory cannot be reactivated, may reflect the complete decay of the memory trace. Future studies could test this possibility by examining the levels of pMAPK expression in the amygdala at different time points following learning. We would expect that the level of pMAPK expression decreases over time until the point where no pMAPK activity is observed, thus reflecting the complete and permanent loss of memory.

\section{When infantile forgetting does not occur}

Although infantile amnesia is one of the strongest, and most frequently observed, characteristics of infant memory, there appear to be some circumstances where infants exhibit much longerlasting retention of early experiences. A largely ignored area of research has been the interaction between early adversity and the development of memory. This is an important gap in the literature considering that early adversity has been shown to be associated with alterations in the developmental trajectory of neural regions important for memory (e.g., Gee et al. 2013). Whether infantile amnesia remained a characteristic of memory development following early life adverse rearing (i.e., maternal separation) was recently investigated by Callaghan and Richardson (2012). In that study infant rats were given pairings of a noise CS and a shock US, and tested for their fear of the noise CS either 1 or $10 \mathrm{~d}$ later. Both standard-reared (SR) and maternally separated (MS) rats learned the association, as both expressed fear at the 1-d interval. However, while the SR rats rapidly forgot the association, expressing negligible levels of CS-elicited freezing just $10 \mathrm{~d}$ later, MS infant rats maintained a high level of fear at the 10-d interval. The MS rats trained as infants continued to express conditioned fear up to $30 \mathrm{~d}$ after the conditioning episode (i.e., well into the young adult period of development), suggesting that MS drastically enhances retention of infant memories. Enhanced memory retention was also observed if animals were reared by mothers who had their drinking water supplemented with the stress hormone corticosterone across the same period of time (i.e., postnatal days 2-14). Thus, early exposure to stress appears to alter the developmental trajectory of memory, accelerating the emergence of adult-like retention, leading to lasting behavioral expression of learned experiences (also see Cowan et al. 2013). These findings have both clinical and theoretical significance. Clinically, these findings might provide at least a partial explanation for why early life adversity is associated with later anxiety disorders (e.g., McLaughlin et al. 2012) as such individuals may explicitly retain their early experiences much longer than normally occurs. Theoretically, these findings may provide a novel approach toward studying the molecular and structural processes involved in memory (e.g., Callaghan et al. 2014). That is, animals exposed to early life adversity may exhibit a markedly different developmental profile in the maturation of one, or more, of these processes. Another area of future research could be to examine whether these effects of maternal separation on retention are observed for all memories, including appetitive ones or are specific to aversive memories.

\section{Conclusions}

Infantile amnesia is a robust and ubiquitous phenomenon; however, there are still many unanswered questions about the nature of infant memories. One of those questions is how early memories, despite being forgotten on a behavioral level, continue to have effects on the animal's physical and mental health later in life. In this review, we presented evidence suggesting a neural trace of the experience persists even when memories are no longer recalled or expressed. This finding highlights the importance of considering what the term "forgetting" actually means-is it merely the absence of behavioral expression or is it when even "implicit" effects on later performance are no longer observable? We suggest that forgetting, at least nonreversible and permanent forgetting, occurs when both of these characteristics are observed.

In this review, we hypothesized that the "implicit" effects of early memories on later performance are due to the persistence of the neural signature representing that memory. What we currently do not know is how long these physical traces last. Kim et al. (2012) only examined pMAPK levels $2 \mathrm{~d}$ after training, and it is possible that heightened pMAPK activity in the amygdala is observed weeks, months, or even years later. This would be exciting on a clinical level because we could reactivate and potentially extinguish aversive or traumatic early memories rather than allowing the memories to persist in their implicit form, with their attendant consequences which are not attributed to a specific experience as that memory is not explicitly recalled. Future research also needs to determine how reactivation/reminder treatments interact with the memory trace. It may be that periodic reminders ward off the decay of the memory by working to stabilize the memory trace. This is of interest clinically because it may explain how some early memories are more resilient to disruption than others. Additional research into these persisting neural markers of memory will hopefully provide us with greater insight into how some memories may, indeed, last a lifetime. Overall, this review shows that while the study of infantile amnesia in the last 50 yr has focused predominantly at the behavioral level, our exploration of the phenomenon on a mechanistic level is only just beginning.

\section{Acknowledgments}

Preparation of this manuscript was supported by grants from the Australian Research Council (DP120104925) and the National Health and Medical Research Council (APP1031688) to R.R.

\section{References}

Callaghan B, Richardson R. 2012. The effect of adverse rearing environments on persistent memories in young rats: Removing the brakes on infant fear memories. Transl Psychiatry 2: e138.

Callaghan BL, Li S, Richardson R. 2014. The elusive engram: What can infantile amnesia tell us about memory? Trends Neurosci 37: $47-53$.

Campbell BA, Campbell EH. 1962. Retention and extinction of learned fear in infant and adult rats. J Comp Physiol Psychol 55: 1-8.

Campbell BA, Jaynes J. 1966. Reinstatement. Psychol Rev 73: 478-480.

Champagne FA, Curley JP. 2009. Epigenetic mechanisms mediating the long-term effects of maternal care on development. Neurosci Biobehav Rev 33: 593-600.

Cowan CSM, Callaghan BL, Richardson R. 2013. Acute early-life stress results in premature emergence of adult-like fear retention and extinction relapse in infant rats. Behav Neurosci 127: 703-711.

Davis JM, Rovee-Collier CK. 1983. Alleviated forgetting of a learned contingency in 8-week-old infants. Dev Psychol 19: 353-365.

Fraley RC, Roisman GI, Haltigan JD. 2013. The legacy of early experiences in development: Formalizing alternative models of how early experiences are carried forward over time. Dev Psychol 49: 109-126.

Frankland PW, Kohler S, Josselyn SA. 2013. Hippocampus neurogenesis and forgetting. Trends Neurosci 36: 497-503.

Gale GD, Anagnostaras SG, Godsil BP, Mitchell S, Nozawa T, Sage JR, Wiltgen B, Fanselow MS. 2004. Role of the basolateral amygdala in the storage of fear memories across the adult lifetime of rats. J Neurosci 24: 3810-3815.

Gee DG, Gabard-Durnam LJ, Flannery J, Goff B, Humphreys KL, Telzer EH, Hare TA, Bookheimer SY, Tottenham N. 2013. Early developmental emergence of human amygdala - prefrontal connectivity after maternal deprivation. Proc Natl Acad Sci 110: 15638-15643.

Goff B, Gee DG, Telzer EH, Humphreys KL, Gabard-Durnam L, Flannery J, Tottenham N. 2013. Reduced nucleus accumbens reactivity and 
adolescent depression following early-life stress. Neuroscience 249: 129-138.

Graham BM, Richardson R. 2011. Fibroblast growth factor-2 alters the nature of extinction. Learn Mem 18: 80-84.

Han J-H, Kushner SA, Yiu AP, Cole CJ, Matynia A, Brown RA, Neve RL, Guzowski JF, Silva AJ, Jossleyn SA. 2007. Neuronal competition and selection during memory formation. Science 316: 457-460.

Han J-H, Kushner SA, Yiu AP, Hsiang H-L, Buch T, Waisman A, Bontempi B, Neve RL, Frankland PW, Jossleyn SA. 2009. Selective erasure of a fear memory. Science 323: 1493-1496.

Hardt O, Wang S-H, Nader K. 2009. Storage or retrieval deficit: The yin and yang of amnesia. Learn Mem 16: 224-230.

Haroutunian V, Riccio DC. 1977. Effect of arousal conditions during reinstatement treatment upon learned fear in young rats. Dev Psychobiol 10: $23-32$.

Hartley CA, Phelps EA. 2013. Fear models in animals and humans. In Pediatric anxiety disorders (ed. Vasa RA, Roy AK), pp. 3-21. Springer, New York.

Hayne H. 2004. Infant memory development: Implications for childhood amnesia. Dev Rev 24: $33-73$.

Hayne H, Jack F. 2011. Childhood amnesia. Wiley Interdiscip Rev Cogn Sci 2: $136-145$.

Jacobs WJ, Nadel L. 1985. Stress-induced recovery of fears and phobias. Psychol Rev 92: 512-531.

Josselyn SA, Frankland PW. 2012. Infantile amnesia: A neurogenic hypothesis. Learn Mem 19: 423-433.

Kandel ER. 2001. The molecular biology of memory storage: A dialogue between genes and synapses. Science 294: 1030-1038.

Kim JH, McNally GP, Richardson R. 2006. Recovery of fear memories in rats: Role of the $\gamma$-amino butyric acid (GABA) in infantile amnesia. Behav Neurosci 120: 40-48.

Kim JH, Li S, Hamlin AS, McNally GP, Richardson R. 2012. Phosphorylation of mitogen-activated protein kinase in the medial prefrontal cortex and the amygdala following memory retrieval or forgetting in developing rats. Neurobiol Learn Mem 97: 59-68.

Li S, Richardson R. 2013. Traces of memory: Reacquisition of fear following forgetting is NMDAr-independent. Learn Mem 20: 174-182.

Liu D, Diorio J, Tannenbaum B, Caldji C, Francis D, Freedman A, Sharma S, Pearson D, Plotsky PM, Meaney MJ. 1997. Maternal care, hippocampal glucocorticoid receptor gene expression and hypothalamic pituitary-adrenal responses to stress. Science 227: 1659-1662.

Lloyd ME, Newcombe NS. 2009. Implicit memory in childhood.

Reassessing developmental invariance. In The development of memory in infancy and childhood (ed. Courage ML, Cowan N), pp. 93-113. Taylor \& Francis, New York.

Markiewicz B, Kucharski D, Spear NE. 1986. Ontogenetic comparison of memory for pavlovian conditioned aversions to temperature, vibration, odor, or brightness. Dev Psychobiol 19: 139-154.

McLaughlin KA, Greif Green J, Gruber MJ, Sampson NA, Zaslavsky AM, Kessler RC. 2012. Childhood adversities and first onset of psychiatric disorders in a national sample of US adolescents. Arch Gen Psychiatry 69: $1151-1160$.

Mineka S, Zinbarg R. 2006. A contemporary learning theory perspective on the etiology of anxiety disorders. Am Psychol 61: 10-26.

Moscovitch M. 2010. Consciousness and memory in amnesia. In Encyclopedia of consciousness (ed. Banks WP), pp. 183-192. Academic Press, Oxford, UK.

Ofen N, Shing YL. 2013. From perception to memory: Changes in memory systems across the lifespan. Neurosci Biobehav Rev 37: $2258-2267$.

Rovee-Collier C, Cuevas K. 2009. Multiple memory systems are unnecessary to account for infant memory development. An ecological model. Dev Psychol 45: 160-174.

Sanders MJ, Fanselow MS. 2003. Pre-training prevents context fear conditioning deficits produced by hippocampal NMDA receptor blockage. Neurobiol Learn Mem 80: 123-129.

Schacter DL, Buckner RL. 1998. Priming and the brain. Neuron 20: $185-195$.

Schafe GE, Nader K, Blair HT, LeDoux JE. 2001. Memory consolidation of Pavlovian fear conditioning: A cellular and molecular perspective. Trends Neurosci 24: 540-546.

Sevelinges Y, Sullivan RM, Messaoudi B, Mouly A-M. 2008. Neonatal odor-shock conditioning alters the neural network involved in odor fear learning at adulthood. Learn Mem 15: 649-656.

Spear NE, Parsons PJ. 1976. Analysis of a reactivation treatment: Ontogenetic determinants of alleviated forgetting. In Processes in animal memory (ed. Medin DL, et al.), pp. 135-165. Lawrence Erlbaum Associates, Hillsdale, NJ.

Sroufe AL, Egeland B, Kreutzer T. 1990. The fate of early experience following developmental change: Longitudinal approaches to individual adaptation in childhood. Child Dev 61: 1363-1373.

Wiltgen BJ, Wood AN, Levy B. 2011. The cellular mechanisms of memory are modified by experience. Learn Mem 18: 747-750.

Received October 31, 2013; accepted in revised form December 17, 2013. 


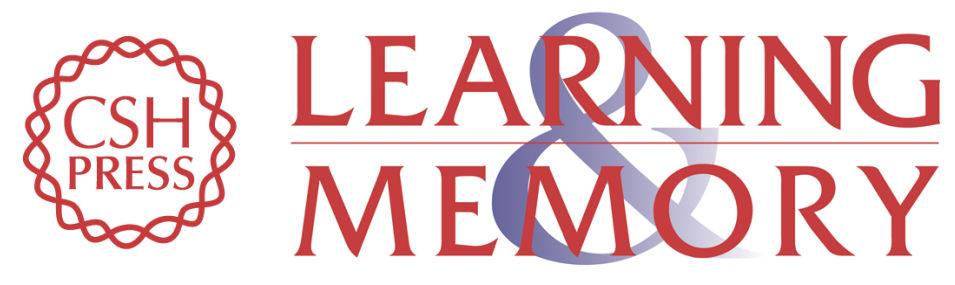

\section{Infantile amnesia: forgotten but not gone}

Stella Li, Bridget L. Callaghan and Rick Richardson

Learn. Mem. 2014, 21:

Access the most recent version at doi:10.1101//m.031096.113

References This article cites 37 articles, 10 of which can be accessed free at: http://learnmem.cshlp.org/content/21/3/135.full.html\#ref-list-1

Creative This article is distributed exclusively by Cold Spring Harbor Laboratory Press for the Commons first 12 months after the full-issue publication date (see

License http://learnmem.cshlp.org/site/misc/terms.xhtml). After 12 months, it is available under a Creative Commons License (Attribution-NonCommercial 3.0 Unported), as described at http://creativecommons.org/licenses/by-nc/3.0/.

Email Alerting Receive free email alerts when new articles cite this article - sign up in the box at the Service top right corner of the article or click here. 